\title{
Mujeres e Iglesia Católica en los años cuarenta. La gestación de una nueva moral.
}

YOLANDA PADILLA RANGEL

Departamento de Historia UAA/El Colegio de Michoacán."

EL GOBIERNO ALEMANISTA Y EL PROCESO DE MODERNIZACIÓN SOCIAL

IVIiguel Alemán heredó un México con rasgos que prevalecerían durante un buen tiempo: presidencia y partido oficial fortalecidos, organizaciones campesinas y obreras subordinadas, industrialización incipiente y confianza de la iniciativa privada en el gobierno. En la tarea de gobernar, Alemán se hizo ayudar de un "gabinete técnico" compuesto por universitarios, con cuyo auxilio pretendió modernizar e industrializar al país, en medio de un ambiente anticomunista, moralista, de culto al dinero y corrupción ${ }^{2}$. Durante estos años se consolidó la élite política de origen revolucionario, que se desenvolvió en medio de un ambiente de simulación, derroche y poderío que tenía como principal escenario la ciudad ${ }^{3}$.

1. Este artículo está basado en los avances de investigación que ha presentado la autora como parte de su tesis de doctorado en ciencias sociales en El Colegio de Michoacán, tesis en la que se observa el proceso de recomposición eclesial en Aguascalientes, después del movimiento cristero.

2. Hay que destacar que la corrupción que se generó durante este sexenio hizo que, en 1952, el nuevo presidente, Adolfo Ruiz Cortines, asumiera el poder en medio de una gran ola de críticas a su antecesor, tanto por la corrupción como por la crisis económica que había dejado en el país.

3. Al respecto puede citarse la novela testimonial de Carlos Fuentes La región más transparente, que relata el ascenso de la burguesía revolucionaria al poder y que refleja 
El presidente puso énfasis en la industrialización del país. También se propuso democratizarlo, pero con un presidencialismo poderoso (que en cierta forma le correspondía reforzar), poco pudo hacer. Algunos analistas aseguran que, aunque el régimen se había propuesto la democratización, lo que en realidad se dio fue el endurecimiento político, que se tradujo en una modernización del autoritarismo presidencial ${ }^{4}$.

Alemán promovió también la doctrina de la "mexicanidad", que fue postulada para combatir los últimos resabios de socialismo cardenista, especialmente el de Vicente Lombardo Toledano, que ahora era considerado como un estorbo para el proyecto presidencial de estímulo a la iniciativa privada y colaboración económica con los Estados Unidos ${ }^{5}$. La ideología de la mexicanidad también fue una compensación simbólica contra la creciente dependencia económica que México estaba asumiendo frente a los Estados Unidos. Esta doctrina, aunque tuvo motivaciones políticas, dio lugar a que algunos escritores se preocuparan por tratar de encontrar la "esencia" y la "identidad" de los mexicanos.

Entre 1940 y 1950 la población de México aumentó en más de diez millones de personas. Este crecimiento estuvo acompañado por una oleada de urbanización que respondía también al traslado de millones de campesinos hacia las ciudades. La economía experimentó una mejora que se expresó en el incremento de los niveles de bienestar nacional. El antropólogo Oscar Lewis observaba entonces:

el universo que describe: "arribista, simulador y poderosamente joven". Ver la novela misma y la entrevista al autor en Emilio Carballido, Protagonistas de la literatura mexicana, SEP, México, 1986.

4. Luis Medina, Civilismo y modernización del autoritarismo, en Historia de la Revolución Mexicana, 1940-1952, El Colegio de México, México,1982, prólogo.

5. Tzvi Medin, "El laberinto de la mexicanidad en el sexenio de Miguel Alemán", en La Jornada Semanal, número 175, 18 de octubre de 1992, pp. 16-25. Gracias a la política presidencial y a una cierta animadversión generalizada en su contra, el lombardismo fue perdiendo fuerza hasta convertirse en una oposición sólo simbólica, mientras que el PRI continuó su consolidación. 
cada vez más aumenta el número de población rural que duerme en cama en lugar de dormir en el suelo, usa zapatos en lugar de huaraches o en vez de ir descalzos, usa pantalones comprados en la tienda en lugar de los calzones blancos de hechura hogareña, come pan además de tortillas, muele su maíz en el molino en vez de hacerlo a mano, bebe cerveza en lugar de pulque. utiliza médicos en vez de utilizar curanderos y viaja en autobús o en tren en lugar de caminar a pie o en burro. En los pueblos y ciudades el cambio ha sido de adobe a cemento, de ollas de barro a ollas de aluminio, de cocinar con carbón a cocinar con gas, de comer con tortillas de maíz a comer con cubiertos, del metate a la batidora eléctrica, de los fonógrafos a la radio y a la televisión, del algodón al nylon y del mezcal al whisky ${ }^{6}$.

Este proceso de modernización no disminuyó la desigualdad social. Por ejemplo, algo que no evolucionó a la par que el crecimiento demográfico fue la vivienda. Las condiciones de vivienda eran deplorables, sobre todo en los barrios pobres de las grandes ciudades y, con el aumento de población y urbanización se suscitó el apiñamiento. Además, según el censo oficial, para 1950 más del 60 por ciento de la población nacional continuaba pobremente alimentada, pobremente alojada y pobremente vestida; el 45 por ciento era analfabeta y el 46 por ciento de los niños en edad escolar no asistía a la escuela; el 85 por ciento de las familias mexicanas tenían ingresos menores a 600 pesos al mes.

Un aspecto importante de la época fue la influencia de la cultura de los Estados Unidos en la cultura mexicana, particularmente en la clase media urbana. El incremento del turismo estadounidense a México (por las nuevas carreteras), las grandes inversiones de los Estados Unidos en México y la instalación de grandes tiendas comerciales en el país, como Woolworth y Sears fueron factores que incidieron en que tal influencia cultural se acentuara en una buena parte de la población. Esta influencia se manifestó en la adopción de ciertas costumbres estadounidenses, por ejemplo, el horario corrido en algunos establecimientos comerciales, ciertos hábitos

6. Oscar Lewis, Antropología de la pobreza. Cinco familias, FCE, México, 1961, pp. 21-22. 
alimenticios, la forma de celebrar la Navidad, etc. Otra fuente de influencia cultural estadounidense fueron los migrantes mexicanos que iban a trabajar temporal o permanentemente a Estados Unidos: entre 1942 y 1955, cerca de un millón y medio de mexicanos emigraron como braceros o agricultores temporales al país del norte, sin incluir en esta cifra a los migrantes que cruzaban la frontera ilegalmente?. La difusión del inglés comenzó a incrementarse.

Las comunicaciones también se modernizaron. Durante los años cuarenta se desarrollaron las carreteras, la navegación y la aviación, desplazando un poco el tradicional auge de los ferrocarriles. El radio y el cine extendieron sus alcances a todo el país (la televisión apareció a principios de los años cincuenta) y tuvieron gran influencia cultural, al ganar cada vez más la atención y el tiempo de las personas que participaban en actividades religiosas que, hasta entonces, constituían la principal actividad social, particularmente en los pequeños pueblos y en los barrios tradicionales de las ciudades 8 .

A pesar de que los sacerdotes lo consideraban impulsor de malas costumbres, el cine se encargó de difundir ciertos valores tradi-

\section{Idem.}

8. Este desarrollo de las comunicaciones "tuvo consecuencias trascendentales para la vida de la Iglesia Católica en México, y debe mencionarse como uno de los elementos más importantes para la comprensión de la actitud social de dicha institución, durante esos años”. Como dice Luis González, con la construcción de caminos en las décadas de los años cuarenta y cincuenta las visitas del obispo se hicieron más frecuentes a San José de Gracia. Allí mismo, comenzaron también, en 1944, las funciones regulares de cine, que los sacerdotes consideraban como "una escuela de malas costumbres" (Ver Luis González, Pueblo en Vilo, El Colegio de México, México, 1972, p. 207, 209 y 242-243. Citado también en Roberto Blancarte, Historia de la Iglesia Católica en México, FCE, México, 1991, p. 65). Con el cine y la televisión, las parroquias vieron alteradas sus costumbres pues, por ejemplo, la asistencia al rosario disminuyó, por lo que algunos sacerdotes se resistieron inicialmente a aceptar estos medios de comunicación y siguieron prefiriendo a la prensa, por medio de la cual realizaron una gran campaña para seguir difundiendo sus ideas, particularmente a través de la Obra Nacional de la Buena Prensa, que tuvo gran difusión en esta época. Y aunque gran parte de la población no sabía leer, las publicaciones de la Iglesia se leían en los círculos de estudio que proliferaron por doquier en el seno de la Acción

126 C C A A 
cionales, así como la ideología de la mexicanidad. Por ejemplo, en la entonces muy vista película en que actuaba Joaquín Pardavé, Primero soy mexicano, la mexicanidad se planteaba como un asunto de incontaminación, de provincialismo agresivamente anticapitalino, donde ser mexicano significaba "ser analfabeta, filicida, mocho y xenófobo" ${ }^{9}$. Así también, en esa película:

El mexicano es definido por sus esencias -su afición familiar y calor personal, además de la comida, la ropa, la música y la lengua- no por su formación histórica. Al final de la película, cuando Rafael [el personaje principal] se incorpora a la mexicanidad, lo hace a través de enchilarse con tacos de chicharrón y chỉle verde, vestirse como charro, cantar corridos y, más que nada, regresar a la familia como hijo obediente, arrodillado ante su padre ${ }^{10}$.

A pesar de los estereotipos esencialistas de mexicanidad y de familia difundidos por esta película, la situación real era ambigua, por ser cambiante. Para ilustrar esa afirmación puede citarse el éxito que tuvo el cómico Tin Tan, quien en películas como El Rey del Barrio, contrariamente a lo propuesto en Primero soy mexicano, ridiculizaba la familia como institución, no reivindicaba a la madre omnipresente y era irreverente ante el mundo "decente" de la época. Significativo es que, en vez de reivindicar a la familia como principal pilar de la sociedad, Tin Tan proponía en esta película que la fuente de sustento social era el barrio. En un contexto social de fuerte industrialización, migración y urbanización, los barrios

Católica. La Obra Nacional de la Buena Prensa publicó entre 1936 y 1941 más de 66 millones de números de revistas, folletos, libros y sobre todo hojas de divulgación. La Acción Católica publicó en 1939, 10 mil ejemplares de las encíclicas Rerum Novarum y Quadragesimo Anno. Los lectores de estas publicaciones eran sobre todo urbanos y con mediana instrucción. Para 1946 la ONIR había alcanzado tirajes de 47 mil ejemplares y Cultura Cristiana de 162 mil 500 ejemplares por edición, lo cual muestra los alcances de la labor editorial de la Iglesia en esta época.

9. Cita a Emilio García Riera en John Mraz, "Lo gringo en el cine mexicano y la ideología alemanista" en Revista Crisol, número 82, Aguascalientes, diciembre de 1996, pp. 40-44.

10. John Mraz, art. cit. p. 41. 
en las ciudades vinieron a suplantar a los pueblitos de los migrantes. Así, al esencialismo atemporal de la familia y lo mexicano, Tin Tan oponía la solidaridad entre los pobres mexicanos del barrio, a partir del contexto histórico en que vivían ${ }^{11}$.

\section{El FORMALISMO MORAL Y LA "DECENCIA" FEMENINA}

Otro aire que flotaba en el ambiente de los años cuarenta era el del formalismo en las relaciones sociales y personales. El gusto por las formas era tal, que llevó a Octavio Paz a escribir lo siguiente: "En cierto sentido, la historia de México, como la de cada mexicano, consiste en una lucha entre las formas y fórmulas en que se pretende encerrar a nuestro ser y las explosiones con que nuestra espontaneidad se venga"12. No solamente en la historia veía Paz el predominio del formalismo, sino también en la política, en el arte y en las relaciones cotidianas, esferas en las que veía que imperaban "el pudor, el recato y la reserva ceremoniosa". El pudor era algo generalizado, pero en el caso de las mujeres, se convertía en una virtud:

las miradas extrañas nos sobresaltan, porque el cuerpo no vela intimidad, sino la descubre. El pudor, así, tiene un caracter defensivo, como la muralla china de la cortesía o las cercas de órganos y cactus que separan en el campo a los jacales de los campesinos. Y por eso la virtud que más estimamos

11. Idem. El personaje de Tin Tan es un pachuco, es decir, un migrante que ha recibido la influencia de la cultura estadounidense, lo cual le da la base para tener otra visión de su propia cultura. El personaje es también un irreverente hacia el gobierno, por lo que el actor se ganó los reproches de varios funcionarios, pero que, según Mraz, le aseguró su lugar como un cómico urbano irreverente, cosmopolita, autorreflexivo y moderno en el cine mexicano.

12. Octavio Paz, El laberinto de la soledad, FCE, México, 1973, p. 29. Este libro se publicó por vez primera en 1950, por lo que refleja muy bien las preocupaciones y concepciones que sobre la sociedad tenían los escritores de la época, influidos quizá por el debate sobre la mexicanidad que se daba en el ámbito político, pero también en el filosófico. 
en las mujeres es el recato, como en los hombres la reserva. Ellas también deben defender su intimidad ${ }^{13}$.

Parecía que los hombres otorgaban a las mujeres un papel pasivo en la sociedad y en la vida cotidiana. Paz decía, por ejemplo, que los mexicanos consideraban a la mujer como un instrumento, "ya de los deseos del hombre, ya de los fines que le asigna la ley, la sociedad o la moral. Fines, hay que decirlo, sobre los que nunca se le ha pedido su consentimiento". Se consideraba que la mujer asumía o debía asumir pasivamente estos fines y valores, como depositaria de ellos, sin capacidad para crear otros distintos. "En un mundo hecho a la imagen de los hombres, la mujer es sólo un reflejo de la voluntad y el querer masculinos".

La mexicana simplemente no tiene voluntad. Su cuerpo duerme y sólo se enciende si alguien lo despierta. Nunca es pregunta, sino respuesta, materia fácil y vibrante que la imaginación y la sensualidad masculina esculpen. Frente a la actividad que despliegan las otras mujeres, que desean cautivar a los hombres a través de la agilidad de su espíritu o del movimiento de su cuerpo, la mexicana opone un cierto hieratismo, un reposo hecho al mismo tiempo de espera y desdén. El hombre revolotea a su alrededor, la festeja, la canta, hace caracolear su caballo o su imaginación. Ella se vela en el recato y la inmovilidad. Es un ídolo. Como todos los ídolos, es dueña de fuerzas magnéticas, cuya eficacia y poder crecen a medida que el foco emisor es más pasivo y secreto. Analogía cósmica: la mujer no busca, atrae. Y el centro de su atracción es su sexo, oculto, pasivo. Inmóvil sol secreto ${ }^{14}$.

En este sentido, la mujer no sólo debía ocultarse, sino ofrecer cierta "impasibilidad sonriente" al mundo exterior. Ante el escarceo erótico, debía ser "decente"; ante la adversidad, debía ser "sufrida". Pero estas respuestas no eran instintivas ni personales, sino conforme a un modelo genérico: así debían responder las mujeres. $\mathrm{Y}$ ese modelo subrayaba los aspectos defensivos y pasivos, en una

13. Idem., p. 31.

14. Idem., pp. 31-33. 
gama que iba desde el pudor y la "decencia" hasta el estoicismo, la resignación y la impasibilidad.

En la vida diaria, su función consiste en hacer imperar la ley y el orden, la piedad y la dulzura. Todos cuidamos que nadie "falte el respeto a las señoras", noción universal, sin duda, pero que en México llevamos hasta sus últimas consecuencias (...). Naturalmente habría que preguntar a las mexicanas su opinión; ese 'respeto' es a veces una hipócrita manera de sujetarlas e impedirles que se expresen ${ }^{15}$.

Tal vez las mujeres no desempeñaron el papel pasivo que se esperaba ejecutaran. Las mujeres desempeñaron un papel activo en las transformaciones que experimentó la vida familiar, por ejemplo, el desplazamiento del padre por la madre como la figura dominante en la familia, el aumento de libertad a los niños, una mejoría constante del nivel de vida mediante las compras en abonos, mayores oportunidades para la diversión, relaciones sociales más amplias y una gradual modernización en muchas creencias ${ }^{16}$. Además, durante los años cuarenta, las mujeres desempeñaron un papel protagónico, particularmente en el ámbito eclesial, que era en el que principalmente podían expresarse, coadyuvando con esto a la recuperación de una Iglesia Católica que, en los años previos, había experimentado los embates anticlericales del Estado mexicano postrevolucionario.

\section{LA IMPORTANCIA DE LAS MUJERES \\ EN LA RECOMPOSICIÓN ECLESIAL}

En los años cuarenta, gran parte de vida eclesial giraba en torno a una organización seglar: la Acción Católica (AC). Esta organización era considerada por la jerarquía como un instrumento necesarísimo de ayuda a los sacerdotes. En el origen de la asociación estaban

15. Idem., p. 34 .

16. Idem., p. 27.

130 C C A 
dos causas: por una parte la escasez de sacerdotes a nivel mundial, que hizo que la jerarquía pusiera sus ojos en la ayuda que el seglar le podría proporcionar en el combate a la secularización de las costumbres cristianas y, por otra parte, en el caso mexicano, las ataduras legales a que estaba sujeta la Iglesia Católica, que hicieron que los seglares fueran vistos como unos actores católicos que podrían incidir en donde el clero no lo podía hacer.

Debido al fuerte conflicto Iglesia-Estado que había dado origen al movimiento cristero, la Acción Católica no consideraba dentro de su horizonte a la acción política, sino que buscaba más bien un tipo de acción cívico-religiosa que no suscitara ningún tipo de conflicto con el Estado. Por esta razón, varios católicos varones no se sintieron atraídos por la organización, en la que poco participaron y algunos hasta se retiraron para ingresar en organizaciones de tipo político, como por ejemplo el PAN. Muchas mujeres, en cambio, se sintieron atraídas por el tipo de acción cívico-religiosa que realizaba la asociación. Por eso fue la rama femenina de la Acción Católica, esto es, la Unión Femenina Católica Mexicana, la que se constituyó en el brazo fuerte de la jerarquía, pues era la organización que más participantes logró conglomerar y la que más actividad demostró, todo dentro del esquema de subordinación y obediencia a los párrocos y obispos. La Acción Católica desplegaba toda su actividad teniendo como eje central la vida parroquial. Por esto ambas instancias se convirtieron en fuertes pilares de la recomposición eclesial.

La organización de los católicos en torno a los párrocos y a la jerarquía, a través de la Acción Católica, tuvo un éxito desigual. Aunque la mayoría de los párrocos se abocaron obedientes a la organización de la $\mathrm{AC}$, algunos obispos y sacerdotes mostraron reticencias. Los laicos también expresaron una respuesta diversificada. Los jóvenes varones y los hombres adultos no se incorporaron fácilmente a la asociación, mientras que las jóvenes y las mujeres adultas se incorporaron rapidamente e hicieron florecer la rama femenina. La respuesta hacia la AC fue diferenciada por género, al 
tiempo que el protagonismo en el florecimiento de la organización lo desempeñaron las mujeres, quienes parecían sentirse muy a gusto en la acción cívica, religiosa y despolitizada.

La organización que antecedió a la Juventud Católica Femenina Mexicana fue la de las Hijas de María y la que antecedió a la Unión Femenina Católica Mexicana la de las Damas Católicas. En el caso de las ramas masculinas de la AC, los contingentes iniciales provinieron de la Adoración Nocturna y de la primera ACJM. En la época de la AC perdieron presencia asociaciones como los Obreros Guadalupanos, los Caballeros de Colón, las Congregaciones Marianas y las Terceras Órdenes Franciscanas. Los pocos hombres que ingresaron a la Acción Católica se vieron desalentadas por el tipo de actividades que se esperaba tenían que desarrollar: edificación de templos, escuelas, seminarios, colectas para fiestas patronales, actividades catequísticas, entronizaciones del Sagrado Corazón y de la Virgen de Guadalupe, campañas de moralidad pública, dispensarios, bazares, etc. Si algún hombre expresaba inquietudes políticas, el párroco se encargaba de encauzarlas hacia estas actividades socio religiosas ${ }^{17}$.

Gracias a la gran actividad desplegada por la AC en las parroquias, la Iglesia comenzó un periodo de expansión y consolidación. Durante el decenio 1940-1950, el porcentaje de católicos en México subió de 96 a 98 por ciento, dato significativo si consideramos que generalmente o se mantenía igual o decrecía ${ }^{18}$. Así también, se erigieron nuevas circunscripciones eclesiásticas y surgieron nuevas parroquias. Cabe mencionar también que los institutos religiosos, particularmente los femeninos, crecieron notable, aunque silenciosamente. Los institutos religiosos, en general, pasaron de ser 63

17. José Miguel Romero de Solís, El Aguijón del Espiritu. Historia contemporánea de la Iglesia en México (1895-1990), Instituto Mexicano de Doctrina Social Cristiana, México, 1994, p. 405.

18. Esto no significa que el número de protestantes, en términos absolutos no haya aumentado, pues de hecho casi se duplicó al pasar de 177 mil 954 a 330 mil 11l. La mayoría de estos protestantes se ubicaba en las iglesias pentecostales. Idem., p. 410. 
en 1940 a 92 en 1950, pero los institutos femeninos pasaron de 39 a 60 en el mismo periodo. Las religiosas incrementaron su número formidablemente: de ser 8,123 en 1945, pasaron a ser 19,400 en 1960, es decir, más del doble en menos de 20 años ${ }^{19}$. Como entre los laicos, el clero regular experimentó también un cambio de protagonistas: si durante la colonia y el siglo XIX habían destacado los institutos religiosos masculinos, ahora, en la mitad del siglo XX, comenzaban a destacar los femeninos.

En conjunto, la Iglesia Católica experimentó una notable expansión durante los años cuarentas y cincuentas, de tal manera que en 1958 se tenían registrados 434 organismos católicos, con un total de 4'530,743 miembros. Veinticuatro de estos organismos estaban clasificados como órdenes seculares y 20 como órdenes pías. Los grupos principales eran la Acción Católica Mexicana, con 348,273 miembros, la mayoría de ellos mujeres; la Unión Nacional de Padres de Familia con 500 mil miembros; los Caballeros de Colón con 3,400 miembros; la Federación de Colegios Particulares, con 112 colegios y escuelas en el DF; la Legión Mexicana de la Decencia (nótese) con 25 miembros en cada una de las 32 entidades federativas; la Asociación Nacional de Periodistas, Escritores, Publicistas y Editores con 425 miembros; la Obra Nacional de la Buena Prensa. ${ }^{20}$.

Siguiendo a Víctor Gabriel Muro hay que decir que la conformación de organizaciones masivas y el engrandecimiento de la estructura eclesial, en los años cuarentas y cincuentas, permitieron a la Iglesia incrementar su influencia en la sociedad civil y su gran capacidad de interlocución con el Estado. En el ámbito político, las

19. Idem., p. 414.

20. Víctor Gabriel Muro, "Estructura y acción renovadora en la Iglesia Católica mexicana contemporánea”, en Revista Nueva Antropología, Vol. XII, no. 41, UAM Iztapalapa, México, marzo de 1992, p. 86. También comenzaron a tener presencia en los años cincuenta el Opus Dei y organizaciones dinámicas que se autodenominaban "movimientos", como el Movimiento Cursillos de Cristiandad y el Movimiento Familiar Cristiano. 
grandes organizaciones laicas desarrollaron un agudo sentimiento antiliberal y antisocialista, aunque como la Iglesia no tenía presencia en el terreno sindical, puede decirse que su ascendencia en este ámbito fue básicamente ideológica. Esta influencia de la Iglesia convergió con el ascenso de las clases medias, por lo que éstas se convirtieron en el eco natural de su ideología. Sin embargo, la veloz expansión cuantitativa no siempre se tradujo en la preparación adecuada de sacerdotes, religiosos, religiosas y laicos, que se podían ubicar siempre dentro de corrientes teológicas "tradicionales"21.

La Iglesia de los cuarenta, más que competir con el Estado por el liderazgo de la sociedad, se replegó en los formalismos de la vida religiosa, convirtiéndose así en una Iglesia a la que el Estado ya no tenía que temer ${ }^{22}$, pues su influencia ahora parecía reducirse al ámbito moral, ya que estaba sumamente preocupada por ganar la batalla contra la secularización de las costumbres cristianas. El Estado, por su parte, a cambio de fingir ceguera ante las constantes violaciones a la ley y comprendiendo que la influencia de la Iglesia estaba centrada ahora en la forma y en la moral, decidió utilizarla para incrementar y consolidar su poder ${ }^{23}$. La Iglesia dejó de ser una amenaza política para el Estado ${ }^{24}$.

Sin embargo la Iglesia era una fuerza social importante en la sociedad mexicana, que encontraba en las mujeres su principal centro energético.

21. Idem., pp. 84-86.

22. José Miguel Romero, "Iglesia y Revolución en México" En Quintín Aldea y Eduardo Cárdenas, Manual de Historia de la Iglesia. La Iglesia del siglo XX en España, Portugal y América Latina, Herder, Barcelona, España, 1987, p. 497.

23. Martaelena Negrete, "La Iglesia y el Estado en México, 1930-1940", en María Alicia Puente, Hacia una historia mínima de la Iglesia en México, Jus-CEHILA, México, 1994, pp. 175-176.

24. Cuamea, Felipe, "La Iglesia Católica en México: del ostracismo a la arena política" mecanoescrito, Doctorado en Ciencias Políticas, Tulane University, USA, 1995, pp. 17-19. 


\section{LA PARTICIPACIÓN DE LAS MUJERES EN LA AC Y LA NUEVA MORAL}

En la tarea de "recristianizar la sociedad", la AC consideró que las mujeres eran imprescindibles. La experiencia histórica indicaba que eran ellas las personas más adecuadas en la tarea de transmitir valores de una generación a otra. En las mujeres parecía radicar la responsabilidad total del comportamiento moral de toda la familia.

Sin embargo, hasta ese momento, la mayoría de las mujeres mexicanas se había desempeñado principalmente en sus funciones de esposas y madres dentro del hogar. Ahora, la Iglesia quería que ejercieran su influencia no sólo en su familia sino más allá de ella, que salieran a otros ámbitos de la sociedad. Con base en este propósito, la Iglesia pretendía que las mujeres se capacitaran y participaran en ámbitos tanto internos como externos al hogar:

toda mujer que se dedique al apostolado, debe dedicarse en primer término a su casa (cita a San Pablo): "si alguna (mujer) no tiene cuidado en su casa, principalmente de los suyos, de sus parientes, ésta ha negado la fe y es peor que un infiel". Yo no creo que entre vosotras haya quienes, por dedicarse al apostolado; descuiden su casa; tenéis un doble apostolado que ejercer, el del hogar, aún en las cosas más pequeñas, y el apostolado exterior ${ }^{25}$.

Esto implicaba para los dirigentes de la AC la preocupación por "preservar" a las mujeres de toda situación -externa al hogar- que pusiera en peligro sus personas y, sobre todo, su moral ${ }^{26}$. Por ejemplo,

25. Palabras del Presbítero Francisco de A. García, Asistente Eclesiástico General de la UFCM de Aguascalientes, expresadas en el retiro de las delegadas a la VIII Asamblea General de la UFCM. Ver vili Asamblea General de la UFCM, 1944-1946, ACM, México, s/f.

26. Valentina Torres, "La educación de la mujer campesina: una visión a través de los métodos y manuales de la ACM (1929-1960)" Ponencia presentada en el XVII Coloquio de Antropología e Historia Regionales titulado La Iglesia Católica en México, organizado por El Colegio de Michoacán, en Zamora, Mich., del 23 al $2 \grave{c}$ de octubre de 1995, pp. 3-5. 
en una ocasión, la comisión de propaganda de la AC había recomendado dar a las "señoritas" trabajos sólo en zonas y domicilios que no les resultaran peligrosos moral o personalmente, ya que dentro de algunas parroquias solían existir zonas de tolerancia, centros de vicio "o al menos inconvenientes para señoritas de cierta edad"27.

Para la AC, una forma de preservar a las mujeres de los peligros de la sociedad era apartarlas de ellos, pero otra —cada vez más necesaria, ya que las mujeres no podían permanecer aisladas- era tratar de garantizar que su conducta se apegara a la moral católica, en cualquier lugar. Por esta razón, además de que la mujer era considerada como la principal transmisora de los valores católicos y la más eficaz defensora contra los nuevos peligros de la sociedad moderna, la formación moral de la.mujer se convirtió en un fin importantísimo para la AC. Se diseñaron acciones para fomentar la moralidad en los planes y programas de la AC, así como la organización de secciones de moralidad en todos los niveles de su estructura.

Así por ejemplo, desde 1933 el plan de trabajo de la AC había establecido un apartado completo sobre moralidad. En él se había escrito que todo miembro de AC debía defender la santidad del matrimonio, para lo cual era necesario instruir a la mujer sobre la importancia de su misión en la vida social y en el hogar, así como instruirla en el desarrollo de su vida espiritual interna, que era el "único remedio radical para los males que nos afligen". El plan también había dispuesto hacer una gran labor contra los vicios que se oponían a la santidad del matrimonio cristiano, por ejemplo, el control de la natalidad, contra el cual se había propuesto difundir la Encíclica de Pío XI sobre el matrimonio cristiano. El Plan había propuesto también realizar una campaña contra el amancebamiento y la prostitución, trabajando por la paz y la santidad del matrimonio, "re-

27. "AC. Comisiones de propaganda", en Boletín Eclesiástico, no. 8, Aguascalientes, Ags., agosto de 1932.

136 圆 C 
conciliando a los esposos que estuvieren separados y ayudándolos a resolver las dificultades ${ }^{9228}$.

Esto a nivel nacional, pero en el nivel parroquial también se habían implementado, desde los años treinta, medidas en torno a la moralidad. Por ejemplo, la sección de moralidad del grupo parroquial del Sagrario, de la UFCM de Aguascalientes, había organizado comités para que todas las socias tuvieran una sólida instrucción religiosa y frecuentaran los sacramentos; para trabajar por la moralización de los espectáculos y para desterrar de la parroquia toda clase de diversiones ofensivas a la moral cristiana; para promover y fomentar reuniones y espectáculos morales; para procurar que en los hogares cristianos no entraran periódicos, novelas, folletines y otras publicaciones que pusieran en peligro la santidad del hogar; para crear bibliotecas circulantes con lecturas de sana moral y para apoyar a las Ligas de Modestia Cristiana, que tenían como fin que la mujer vistiera honestamente ${ }^{29}$.

Aunque los principios básicos y metodológicos de la formación de las mujeres de AC coincidían con los de los hombres (piedad, estudio y apostolado, apoyados con la instrucción a través de clases, círculos de estudios, cursos, conferencias, etc.), había diferencias en el programa de instrucción religiosa y moral. El programa de instrucción religiosa para las mujeres de AC consistía en la enseñanza del catecismo, que se realizaba a través de cartillas o catecismos cuyas preguntas y respuestas se tenían que memorizar. En una de esas cartillas se hacían preguntas como las siguientes:

28. "AC. Plan General de Trabajo para 1933", en Boletín Eclesiástico, núms. 1 y 2, Aguascalientes, Ags., enero y febrero de 1933. Dentro del Plan de Moralidad, a la Unión de Católicos Mexicanos (UCM) se le encomendaba sostener Sociedades de Temperancia entre los hombres, para combatir en ellas el alcoholismo, la prostitución y otros vicios.

29. "Reglamento de la Sección de Moralidad del Grupo Parroquial del Sagrario, de la ufcM.” en Boletín Eclesiástico, núm. 7, Aguascalientes, septiembre de 1931. 
Pregunta: ¿Cuáles son los fines del matrimonio?

Respuesta: El primer fin del matrimonio es tener hijos y educarlos cristianamente. Y el segundo fin es ayudarse mutuamente y evitar los pecados que se cometen cuando viven juntos un hombre y una mujer sin estar casados... Pregunta: ¿Pueden ir solas las hijas al río a traer agua y hacer mandados? Respuesta: Si las hijas son formales y no hay otro remedio, tendrán que ir solas, pero deben los padres aconsejarlas, recomendándoles que no tarden en regresar, que no se detengan a platicar con los muchachos en el camino, ni se vayan por las veredas o por las huertas. Lo mejor será que se acompañen con alguna vecina que sea mujer seria y honrada. Lo mismo se les aconseja para cuando tengan que llevar la comida a los trabajadores ${ }^{30}$.

Un elemento importante para la formación religiosa de las mujeres eran los materiales impresos producidos por la misma AC. Por esta razón, dentro del conjunto de las textos publicados por la $\mathrm{AC}$ entre 1929 y 1960, predominaron los textos (manuales, cartillas, folletos, revistas y periódicos), dirigidos a las mujeres, que formaban el grupo más numeroso dentro de la organización. Los textos, aunque adaptados a la especificidad de cada grupo de mujeres, buscaban difundir los principios y fines generales de la Iglesia y evitar malas interpretaciones de los mismos. También abundaron los escritos sobre las formas de organización de la AC y los manuales para las dirigentes y las militantes. Las mujeres debían saber leer y escribir para poder ser instruidas con catecismos, folletos y otro tipo de publicaciones, para lo cual la AC implementó una campaña alfabetizadora. Por otra parte, para las mujeres que ya sabían leer y escribir existía otro programa que incluía elementos de gramática, aritmética, historia y geografía de México ${ }^{31}$.

El programa de formación moral de los miembros de AC era semejante al programa religioso, ya que moral y religión se confun-

30. ufCM, Cartilla para el matrimonio, Delegación de Campesinas, tercera edición, 1956, p. 3 y ss. citado en Valentina Torres, op. cit., p. 13.

31. Id., p. 5 y ss. 
dían. Por moral la AC entendía "las reglas a que debe sujetarse el hombre para alcanzar su último fin" y la formación moral consistía en lograr la disminución o el exterminio de los vicios. Se consideraban como vicios, entre otros, la embriaguez, la promiscuidad, el amasiato, la discordia y la maledicencia, el odio al patrón, la desconfianza hacia otras clases sociales, el hurto y la pereza. La inmoralidad también era entendida como las faltas al sexto y al noveno mandamiento A los vicios se contraponían los valores tradicionales de la Iglesia ${ }^{32}$.

La moral de la $\mathrm{AC}$ no podía ser otra que la que apuntara al desarrollo de las virtudes centrales de la moral católica, en torno a las cuales se aglutinaban las otras virtudes, a saber: la prudencia o "disposición de la razón práctica a discernir en toda circunstancia el bien y a elegir los medios rectos para realizarlo", la justicia o "firme voluntad de dar a Dios y al prójimo lo que le es debido", la fortaleza o "constancia en la búsqueda del bien" y la templanza que "modera la atracción de los placeres y procura el equilibrio en el uso de bienes creados". Templanza también quiere decir "asegurar el dominio de la voluntad sobre los instintos y mantener los deseos en los límites de la honestidad"33. Esta última virtud era tal vez la que más se enfatizaba en la AC.

Con base en esta moral, las mujeres debían aspirar a ser prudentes, justas, fuertes y "honestas", en el sentido de que debían aprender a controlar sus instintos y darles el cauce que la moral permitía. No es posible saber, por el momento, hasta que grado este ideal se traducía en las prácticas de las mujeres católicas de AC. Lo que sí puede observarse por ahora es un indicador del fenómeno contrario, es decir, de cómo las mujeres incidieron, con sus prácticas, en la gestación de una nueva moral. Por ejemplo, si se toma como

32. Idem., pp. 12 y 13.

33. Catecismo de la Iglesia Católica, Asociación de Editores del Catecismo, IMPRESA, Madrid, 1993, pp. 408-410. 
indicador la forma de vestir de las mujeres, puede observarse que, con el paso del tiempo, algunas mujeres impusieron su forma de vestir sobre las disposiciones que constantemente la jerarquía daba al respecto.

\section{LA PAULATINA AUTONOMÍA DE LAS MUJERES EN SU FORMA DE VESTIR}

Desde los años treintas, la Sagrada Congregación del Concilio había expresado sus preocupaciones y dado instrucciones acerca de lo que consideraba la "deshonestidad" en las modas femeninas ${ }^{34} . \mathrm{Y}$ en las diócesis de México se habían repetido estas preocupaciones. La AC había secundado estas preocupaciones y había creado en el interior de sus ramas femeninas, secciones o "ligas" que se dedicaban a promover la "decencia" en el vestir de las mujeres, organizando campañas que apuntaran a tal fin. Respecto al vestido de las mujeres, las palabras que más indicaban el ideal de la moral católica eran "decencia", "modestia" "honestidad", "moralidad". Pero, ¿qué quería decir esto? A saber, estos términos aludían a una forma de vestir en la que, entre menos se dejara al descubierto el cuerpo de la mujer, mejor. La mujer no debía, con su forma de vestir, "provocar", ni ser "desenvuelta" en su forma de actuar.

El obispo de Aguascalientes decía, en 1944, que era "necesario poner un dique a la corriente de inmoralidad que nos invade con la inmodestia en el vestir y otras costumbres que ponen en inminente peligro la honestidad de nuestros jóvenes". Por esta razón el obispo insistía en que "con suma prudencia" los sacerdotes debían "clamar contra la indecencia en el vestir de las mujeres". Los sacerdotes debían seguir la siguiente instrucción del obispo diocesano:

34. "Instrucción de la Sagrada Congregación del Concilio acerca de la deshonestidad de las modas femeninas", Boletín Eclesiástico, Aguascalientes, Ags., no. 3, 1 de mayo de 1930. 
Háblenles a la conciencia, infundiéndoles el temor de Dios y haciéndoles ver la culpa en que incurre por el escándalo la mujer que se presenta inconvenientemente vestida, provocativa y desenvuelta. Los padres de familia deben contribuir en favor de esta campaña por la decencia, ya que de ellos depende en gran parte el que las esposas y las hijas conserven lo que es para ellos un honor y para ellas la prenda de más valor: el delicado pudor de la mujer ${ }^{35}$.

Aunque, según el obispo de Aguascalientes, José de Jesús López y González, era difícil dar reglas precisas y fijar medidas exactas sobre el vestido de las mujeres, sí pudo fijar siete reglas sobre la forma en que debían vestir y aún dos más sobre la manera en que debían comportarse las mujeres. Sólo cumpliéndolas, decía el obispo, "lograremos contrarrestar la acción del demonio, quien engreído con su triunfo en el paraíso, pretende perder el mundo valiéndose de la mujer". Las reglas eran las siguientes:

1. La falda debe bajar cuando menos cinco centímetros de la rodilla.

2. El escote no debe bajar más de cinco centímetros del nacimiento del cuello.

3. Prohibimos el uso de tobilleras, de los 10 años de edad en adelante.

4. La manga del saco no debe subir del codo.

5. Severamente condenamos la costumbre que empieza a introducirse de prescindir absolutamente de las medias y presentarse con las piemas del todo desnudas. 6. Condenamos también la libertad que se toman algunas mujeres de entrar al templo con el pañuelo en la cabeza, en lugar del velo que debe cubrirlas. 7. Empéñense los sacerdotes en conseguir que las mujeres no usen para entrar al templo, y especialmente para acercarse a la Sagrada Mesa, esos velos tan transparentes que a nada equivalen.

8. Amonesten a los padres de familia para que, por su honor y la pureza de sus hijas, no permitan que asistan a esos bailes en que de tal manera se tratan los dos sexos, que no son sino incentivo de las pasiones.

9. Influyan con su insistencia en los padres de familia para que de ninguna manera toleren que sus hijas salgan de paseo a solas con jóvenes de distinto sexo, por más recomendables que ellos sean; y para que sean prudentes y cristianos, aconsejando y dirigiendo a sus hijas en sus relaciones con los jovenes que seriamente las pretendan ${ }^{36}$.

35. "Circular 321 del gobierno eclesiástico del Obispado de Aguascalientes al venerable clero secular y regular de la Diócesis" en Boletín Eclesiástico, no. 12, diciembre de 1944.

36. Idem. 
Estas reglas estuvieron formalmente vigentes, aunque en la realidad algunas mujeres las cumplían y otras no. En 1947, la idea de este reglamento fue reforzada por medio de una instrucción dada por la Sagrada Congregación del Concilio a la Iglesia Diocesana de Aguascalientes, que se refería al vestido "deshonesto" de las mujeres. La instrucción indicaba a los párrocos insistir en que las mujeres llevaran vestidos que respetaran el pudor y sirvieran "de adorno y defensa a la virtud". La instrucción se dirigía también a los padres de familia, exhortándolos a instruir a sus hijas en la doctrina cristiana y a fomentar en ellas el amor a la modestia y a la castidad; también los exhortaba a que apartaran a sus hijas de juegos públicos y de luchas gimnásticas. La instrucción se dirigía también a personajes que por entonces estaban cobrando mayor importancia, las directoras y maestras de colegios particulares, quienes debían "trabajar por imbuir en las almas de las niñas el amor a la modestia", así como impedir que entraran a sus respectivos colegios niñas que portaran vestidos "deshonestos". Este tipo de vestidos tampoco serían permitidos en oratorios, centros recreativos ni organizaciones piadosas.

La instrucción exhortaba a párrocos y seglares a establecer asociaciones femeninas que tuvieran por fin inhibir el uso de vestidos que no estuvieran de acuerdo con lo que se entendía como modestia cristiana y que, a la vez, promovieran la pureza en las costumbres. Así también, las mujeres que llevaran puesto un vestido "deshonesto", debían ser "apartadas de la Santa Comunión y del oficio de madrinas en los sacramentos del bautismo y la confirmación" y, de plano, debía negárseles la entrada al templo. Los sacerdotes también debían animar a las mujeres para que, en los días de fiesta, vistieran "cristianamente". Por su parte, cada consejo diocesano de la AC debía tratar, por lo menos una vez al año, el tema relativo a los medios más aptos para velar eficazmente por la modestia en las mujeres. Los obispos, a su vez, debían informar anualmente sobre las condiciones y el estado de cosas que, sobre 
la manera de vestir de las mujeres, prevalecía en sus respectivas diócesis ${ }^{37}$.

La AC consideraba que el vestido femenino era mejor en tanto ocultara más el cuerpo de la mujer. Había que mantener ocultos los cuerpos de las mujeres ya que, al parecer, con ello se esperaba que permanecieran inhibidas, o por lo menos ocultas, las pasiones por ellos despertadas. Se consideraba que la manera de vestir de las mujeres era asunto de los sacerdotes, a quienes correspondía decir lo que era bueno y lo que era malo respecto al tipo y formas de las prendas de vestir femeninas, así como vigilar que las mujeres se apegaran a las disposiciones por ellos establecidas al respecto. Enseguida, según los sacerdotes, eran los padres de familia y otras figuras de autoridad en la sociedad como directores(as) y maestros(as), quienes debían hacer que tales disposiciones se cumplieran. En relación a la forma en que los sacerdotes cumplían con su deber de vigilar la forma de vestir de las mujeres tenemos el siguiente testimonio de una mujer de una parroquia de Aguascalientes:

El que no se me olvida es el señor cura Antonio García, el grandotote que era muy trabajoso, porque casi acabó con toda la gente (de la parroquia) del Encino. Ya al último nomás iban 4.65 gentes a misa. Si ibas con pantalón, te corría, si ibas sin manga también, si ibas sin velo también. Y te corría hasta el atrio. Al último la gente estaba tan asustada o enojada con él que ya no iba. No te tenías que sentar al lado de los hombres; si no ponías las manos juntas al comulgar, no te daba la comunión y así. A Esther mi hermana la corrió nomás porque tráa un escotito hasta aquí y le dijo que se lucía de andar encuerada. Le dijo que se saliera y no se salío y al último salío él corriendo y ella dijo: "pues de taruga me espero", y salí́ corriendo hasta el jardín. Pero ¿a quién no correté́?....

37. "Sagrada Congregación del Concilio" en Boletín Eclesiástico, núm. 2, Aguascalientes, Ags., febrero de 1947.

38. Entrevista Yolanda Padilla Rangel/María del Carmen Franco Pedroza, Aguascalientes, Ags., 1 de marzo de 1995. 
La "guerra" por la forma de vestir de las mujeres se desarrolló entre los sacerdotes y los padres de familia contra las mujeres jóvenes. Con el paso del tiempo, puede decirse que esta "guerra" fue ganada por las mujeres, ya que su forma de vestir fue cambiando paulatinamente, imponiéndose el criterio femenino sobre las disposiciones clericales. Las reglas del vestido femenino experimentaron el proceso de secularización. Y las mujeres individualizaron y definieron sus propias reglas, autoafirmándose y reconstruyendo con ello su identidad.

La manera de vestir de las mujeres es, en este caso, un indicador de cambio social importante ya que, además de expresar la moralidad y las creencias respecto al cuerpo humano en general y al propio en particular, es un indicador de los cambios experimentados en las identidades femeninas.

En el caso del México de las primeras dos décadas del siglo XX, puede decirse que fue la presión de los comerciantes y fabricantes la que impulsó el cambio en la forma de vestir masculina, no así en la femenina, que en esta época experimentó pocos cambios. Sin embargo, entre 1920 y 1960, la forma de vestir, tanto de los mexicanos como de las mexicanas experimentó cambios, ya que se vio fuertemente influida por la forma de vestir norteamericana. Esta influencia llegó, tanto por los establecimientos comerciales como por los migrantes mexicanos quienes, vueltos al terruño, traían consigo diferentes vestuarios, que en cierta forma sugerían nuevas identidades. Posiblemente, ello les facilitaban también una nueva manera de entender y reaccionar frente a diferentes situaciones sociales ${ }^{39}$.

39. Fiona Wilson, "Identidad, mujer indígena y mujer rural" Ponencia presentada en el Segundo Encuentro de Investigaciones y Estudios de Género desde Michoacán: Mujeres, género y desarrollo, Morelia, Michoacán, noviembre de 1996, p. 1-3 y 12. Según Fiona Wilson, para la población de origen campesino, el vestirse de mezclilla fue una manera de empezar a construir una nueva identidad laboral -de obrero agrícola o industrial- y una nueva categoría social en el mundo rural: el migrante temporal a EU. Al mismo tiempo, la ropa traída de EU parecía haberse asociado a nuevas

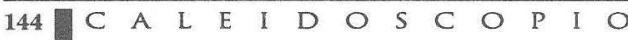


En el segundo tercio del siglo XX, en el Occidente de México, los principales cambios observados en el vestuario femenino fueron los siguientes. Paulatinamente los colores y las texturas se fueron diversificando, así como transformando las prendas de vestir. Los rebozos cada vez fueron más cortos y se usaron menos, limitándose paulatinamente su uso solamente para ir a la iglesia. Las jóvenes comenzaron a vestirse de colores, las faldas se fueron acortando, lo mismo que las mangas de las blusas. Los escotes cada vez fueron descendiendo más. En síntesis, el vestuario femenino fue dejando, poco a poco, más partes del cuerpo de las mujeres al descubierto, lo cual ponía de lado la moral eclesial de que entre más cubierto estuviera éste, mejor.

Por otra parte, la paulatina transformación de las preferencias y el gusto de la población, así como los efectos de la depresión estadounidense de 1929, habían favorecido el desarrollo de la industria de la confección en ciertas regiones de México. Los comerciantes habían comenzado a reducir la venta de rollos de tela de algodón para ofrecer a cambio "cortes" de diferente medida, color y diseño. En diversas localidades mexicanas había aumentado el número de costureras que no sólo hacían las prendas de vestir de las mujeres, sino que también sugerían nuevos diseños. Todo esto ayudó a ampliar el margen de expresión de la individualidad femenina respecto a su propia ropa ${ }^{40}$.

Para observar mejor este cambio en la manera de vestir femenina, puede citarse el caso de Santiago Tangamandapio, comunidad michoacana estudiada por Fiona Wilson. En esta localidad, durante toda la primera mitad del siglo la manera de vestir de las mujeres debía tener siempre la aprobación masculina, particularmente

expresiones de masculinidad. Posteriormente, durante la Segunda Guerra Mundial, los cholos o pachucos mostraron su oposición a la cultura de sus padres a través de su estilo de vida y también a través de su forma de vestir.

40. Idem., pp. 16-18. 
de los sacerdotes, los papás y los hermanos mayores. Así, durante ese periodo el atuendo cotidiano de las mujeres, en el hogar, fue "un vestido casi sin forma y un delantal invariablemente usado". Cuando las mujeres salían de casa, debían usar rebozo para cubrir su cabeza, sus brazos y el mandado (que indicaba el nivel socioeconómico de la familia). En los años sesenta se establecieron en la comunidad talleres de confección de prendas de vestir y las mujeres comenzaron a trabajar en ellos. Durante un buen tiempo, sin embargo, ni siquiera el hecho de que las mujeres obtuvieran un salario modificó su capacidad para decidir sobre su propio vestuario. Fue sólo con el paso del tiempo y poco a poco que las jóvenes solteras empezaron a usar los suéteres que ellas mismas producían y fue sólo hasta la década de los años setenta cuando las mujeres comenzaron a cuestionar las atribuciones ajenas sobre su propio vestuario y a poder determinar lo que era conveniente y respetable desde su propio punto de vista ${ }^{41}$. De acuerdo con la mirada de la antropóloga,

cuando se observa la manera de vestir de las muchachas que acuden cada tarde de domingo a la plaza de Santiago es evidente que ellas han ganado la guerra del vestido... Las jóvenes han utilizado la ropa para sugerir y demandar una forma de vida diferente a la de sus madres... Se trata de un incipiente pero evidente triunfo de la individualidad, es decir, de la capacidad y voluntad de la mujer para expresarse por sí misma, a través de un lenguaje individual ${ }^{12}$.

Lo que interesa resaltar aquí, además del hecho de que el vestido fue fundamental para negociar una nueva identidad femenina, es

41. Idem, pp. 20-21. Al respecto puede verse, también de Fiona Wilson, el libro De la casa al taller. Mujeres, trabajo y clase social en la industria textil y del vestido. Santiago Tangamandapio, El Colegio de Michoacán, México, 1990.

42. Fiona Wilson, “Identidad..." p. 23. 
el proceso de secularización ${ }^{43}$ de la forma de vestir de las mujeres, en el cual ellas le arrebataron a la Iglesia la capacidad de decidir sobre su vestuario. La mujer inició así la gestación de una nueva moral, moderna, individual. A querer y no, la Iglesia Católica, a la larga, terminó por aceptar la secularización del vestido femenino y con ello la gestación de una nueva moral. 0

43. La secularización puede entenderse como el proceso por medio del cual la Iglesia ha ido perdiendo presencia en ámbitos sociales donde antes predominaba, como por ejemplo la política, la ciencia el arte, la educación, etc. y como un proceso por medio del cual los individuos comienzan a ver el mundo y a sus propias vidas sin poner de por medio la visión eclesial. Ver Peter Berger, Para una teoría sociológica de la religión, Kairós, Barcelona, España, 1981. 
